\title{
DEVELOPMENT OF COMBUSTION DYNAMICS AT CO-COMBUSTION OF STRAW WITH WOOD
}

\author{
Harijs Kalis ${ }^{1}$, Antons Kolmickovss ${ }^{2}$, Maksims Marinaki ${ }^{1}$, Liva Ozola ${ }^{1}$ \\ ${ }^{1}$ Institute of Mathematics and Computer Science, University of Latvia, Latvia; \\ ${ }^{2}$ Institute of Physics, University of Latvia, Latvia \\ kalis@lanet.lv,kolmic@lu.lv,maksims.marinaki@lu.lv, liiva@gmail.com
}

\begin{abstract}
The recent research is focused on the experimental study and mathematical modelling of the development of combustion dynamics at thermo-chemical conversion of biomass mixtures (straw with wood pellets) with the aim to better understand the effect of straw co-combustion with wood pellets on the formation of the main gasification/ combustion characteristics. The results of experimental study have shown that thermal interaction between the components at co-combustion of straw with wood pellets at average mass load of straw in the mixture up to 20-30\% promotes faster thermal decomposition of the mixtures and accelerates the flaming combustion of volatiles. The mathematical model considers development of two second order exothermic irreversible chemical reactions at chemical conversion of combustible volatiles $\left(\mathrm{H}_{2}, \mathrm{CO}\right)$ to assess their influence on the development of the combustion dynamics downstream the reacting swirling flame flow. The results of mathematical modelling have shown that, in accordance with the data of the experimental study, the maximal values of the flame temperature, axial flow velocity and the mass fractions of the main products $\left(\mathrm{CO}_{2}, \mathrm{H}_{2} \mathrm{O}\right)$ at the thermo-chemical conversion of the biomass pellets and their mixtures were obtained at 20-30\% of the mass load of straw in the mixture, which is recommended as optimal composition of the mixture.
\end{abstract}

Keywords: biomass pellets, combustion dynamics, chemical reactions, mathematical model.

\section{Introduction}

In terms of the clean energy targets of EU (20-20-20) there is a requirement of $20 \%$ of energy production from the renewable sources. The need for wider use of alternative fuels is growing, e.g., agriculture residues (straw) for energy production providing co-combustion of straw with different types of fuels - wood, coal, peat, etc. [1]. The co-combustion of straw up to $20 \%$ of the energy basis allows partially reduce the operational problems of boilers [2] and reduce the problems related to the enhanced release of polluting $\mathrm{NO}_{x}$ and $\mathrm{CO}$ emission, volatile organic compounds (VOCs) and ash formation comparing to pure straw solid fuel combustion [3; 4]. Nowadays, more efficient methods of use of straw solid fuel are developed around the European Union [2]. Especially, interest for straw utilization for energy production has been raised in Denmark [1] and the United Kingdom [5] by varying the straw proportions in solid or gaseous fuel mixtures. The previous experimental study of straw co-combustion with wood [6] or peat [7] has shown that the main gasification/combustion characteristics of fuel mixtures and composition of emission are strongly influenced by the difference in their elemental and chemical composition and heating values promoting the thermal interaction between the components with direct influence on the thermal decomposition of the mixture, formation, ignition and combustion of volatiles. With this account, the main aim of the current study is to provide more detailed complex experimental study and mathematical modeling of the processes developing at co-combustion of straw with wood pellets to assess the main effects, which influence the main combustion characteristics, produced heat energy and composition of the products at thermochemical conversion of straw mixture with coal by varying the mass load of straw in the mixture.

\section{Mathematical modelling}

For more detailed analysis of the processes developing at co-combustion of straw with wood, mathematical modelling and numerical simulation of the processes is carried out with account of two dominant second-order chemical reactions of volatiles combustion developing downstream of the combustor:

$$
\begin{aligned}
& \mathrm{H}_{2}+\mathrm{OH} \rightarrow \mathrm{H}_{2} \mathrm{O}+\mathrm{H} ; \\
& \mathrm{CO}+\mathrm{OH} \rightarrow \mathrm{CO}_{2}+\mathrm{H} .
\end{aligned}
$$

For mathematical modelling the mass fraction of the main reactants and products in $(1,2)$ are expressed as $C_{k}, k=1(1) 6$. Mathematical modelling and numerical simulation of the main combustion characteristics was carried out using the data of experimental results for the mass fraction of the main 
reactants at the inlet of the combustor with approximation: $C_{1}\left(\mathrm{H}_{2}\right)+C_{2}(\mathrm{OH})+C_{5}(\mathrm{OH})=1, C_{3}\left(\mathrm{H}_{2} \mathrm{O}\right)=$ $C_{4}(\mathrm{H})=C_{6}\left(\mathrm{CO}_{2}\right)=0$.

In accordance with data of the experimental results the average values of the mass fraction of the main reactants $C_{1}\left(\mathrm{H}_{2}\right)$ and $C_{5}(\mathrm{CO})$ at the inlet of the combustor depend on the mixture composition and are as follows: for wood $\mathrm{H}_{2}=0.89, \mathrm{CO}=1.43 \mathrm{~mol} \cdot \mathrm{m}^{-3}$; for $10 \%$ of straw in the mixture $\mathrm{H}_{2}=0.96$, $\mathrm{CO}=2.02 \mathrm{~mol} \cdot \mathrm{m}^{-3}$; for $20 \%$ of straw $-\mathrm{H}_{2}=0.81, \mathrm{CO}=1.86 \mathrm{~mol} \cdot \mathrm{m}^{-3}$; for $30 \%$ of straw $-\mathrm{H}_{2}=0.69$, $\mathrm{CO}=1.54 \mathrm{~mol} \cdot \mathrm{m}^{-3}$; for $100 \%$ of straw $-\mathrm{H}_{2}=1.21, \mathrm{CO}=2.02 \mathrm{~mol} \cdot \mathrm{m}^{-3}$.

The mathematical model uses $1 \mathrm{D}$ approximation of flow velocity $w=u_{z} / U_{0}$, density $\rho$, mass fraction for 6 species and temperature $T / T_{0}$. Numerical simulation is carried out with account of the time-dependent variations of the main flame characteristics downstream of the combustor $\left(x=z / r_{0}\right)$ using MATLAB routine "pdepe" for 9 unknown functions of PDEs.

The production rate of $\mathrm{k}$-th species is expressed as [8]:

$$
\Omega_{k}=\sum_{j=1}^{2}\left[\left(v_{j k}^{\prime \prime}-v_{j k}^{\prime}\right) R_{j}(T) \prod_{n=1}^{6}\left(\frac{\rho C_{n}}{m_{n}}\right)^{v_{j n}^{\prime}}\right], k \in[1,6],
$$

Rate constant of reactions $R_{j}(T)$ in (3) is modified with account of Arrhenius law for temperature dependence of the rate of chemical reactions:

$$
R_{j}(T)=A_{j}^{\prime} T^{\beta_{j}} \exp \left(-E_{j} / R T\right)
$$

where $\left.A^{\prime}{ }_{1}=216, A_{2}^{\prime}=0.96 \cdot 10^{6} \mathrm{~m}^{3} \cdot \mathrm{mol}^{-1} \cdot \mathrm{s}^{-1}\right)$ are the reaction-rate pre-exponential factors;

$E_{1}=14360, E_{2}=30787 \mathrm{~J} \cdot \mathrm{mol}^{-1}$ are the activation energies;

$R=8.314 \mathrm{~J} \cdot \mathrm{mol}^{-1} \cdot \mathrm{K}^{-1}$ is the universal gas constant;

$v_{j k}^{\prime}, v^{\prime \prime}{ }_{j k}$ are the stoichiometric coefficients of $k$-th species (products and reactants) in $j$-th reaction;

$\beta_{j}=0, m_{1}=2, m_{2}=17, m_{3}=18, m_{4}=1, m_{5}=28, m_{6}=44 \mathrm{~g} \cdot \mathrm{m}^{-3}$ are the molecular weights of flame species.

The source term for $C_{k}$ in (3) is $-m_{k} \cdot \Omega_{\mathrm{k}} / \rho 1 \cdot \mathrm{s}^{-1}$. The dimensionless form of PDEs is:

$$
\left\{\begin{array}{l}
\frac{\partial \rho}{\partial t}+\frac{\partial(w \rho)}{\partial x}=e \frac{\partial^{2} \rho}{\partial x^{2}}, \\
\frac{\partial w}{\partial t}+w \frac{\partial w}{\partial x}=-\frac{\partial p}{\partial x}+\operatorname{Re}^{-1} \frac{\partial^{2} w}{\partial x^{2}}, \\
\frac{\partial T}{\partial t}+w \frac{\partial T}{\partial x}=\frac{P_{0}}{\rho} \frac{\partial^{2} T}{\partial x^{2}}+q_{1} \rho A_{1} C_{1} C_{2} T^{b 1} \exp \left(-\frac{\delta_{1}}{T}\right)+q_{2} \rho A_{2} T^{b 2} \exp \left(-\frac{\delta_{2}}{T}\right) C_{2} C_{5}, \\
\frac{\partial C_{1}}{\partial t}+w \frac{\partial C_{1}}{\partial x}=P_{1} \frac{\partial^{2} C_{1}}{\partial x^{2}}-\rho A_{1} C_{1} C_{2} T^{b 1} \exp \left(-\frac{\delta_{1}}{T}\right), \\
\frac{\partial C_{2}}{\partial t}+w \frac{\partial C_{2}}{\partial x}=P_{2} \frac{\partial^{2} C_{2}}{\partial x^{2}}-\rho A_{1} C_{1} C_{2} T^{b 1} \frac{m_{2}}{m_{1}} \exp \left(-\frac{\delta_{1}}{T}\right)-\rho A_{2} C_{2} C_{5} T^{b 2} \exp \left(-\frac{\delta_{2}}{T}\right), \\
\frac{\partial C_{3}}{\partial t}+w \frac{\partial C_{3}}{\partial x}=P_{3} \frac{\partial^{2} C_{3}}{\partial x^{2}}+\rho A_{1} C_{1} C_{2} T^{b 1} \frac{m_{3}}{m_{1}} \exp \left(-\frac{\delta_{1}}{T}\right), \\
\frac{\partial C_{4}}{\partial t}+w \frac{\partial C_{4}}{\partial x}=P_{4} \frac{\partial^{2} C_{4}}{\partial x^{2}}+\rho A_{1} C_{1} C_{2} T^{b 1} \frac{m_{4}}{m_{1}} \exp \left(-\frac{\delta_{1}}{T}\right)+\rho A_{2} C_{2} C_{5} \frac{m_{4}}{m_{2}} T^{b 2} \exp \left(-\frac{\delta_{2}}{T}\right) \\
\frac{\partial C_{5}}{\partial t}+w \frac{\partial C_{5}}{\partial x}=P_{5} \frac{\partial^{2} C_{5}}{\partial x^{2}}-\rho A_{2} C_{2} C_{5} \frac{m_{5}}{m_{2}} T^{b 2} \exp \left(-\frac{\delta_{2}}{T}\right), \\
\frac{\partial C_{6}}{\partial t}+w \frac{\partial C_{6}}{\partial x}=P_{6} \frac{\partial^{2} C_{6}}{\partial x^{2}}+\rho A_{2} C_{2} C_{5} \frac{m_{6}}{m_{2}} T^{b 2} \exp \left(-\frac{\delta_{2}}{T}\right),
\end{array}\right.
$$


where $b_{1}=b_{2}=0, C_{k}$ - mass fractions of species entering the combustor and reactants $\left(\mathrm{H}_{2}, \mathrm{OH}\right.$, $\left.\mathrm{H}_{2} \mathrm{O}, \mathrm{H}, \mathrm{CO}, \mathrm{O}_{2}\right) k=1(1) 6$;

$x=z / r_{0}, w=u_{z} / U_{0}$ are the axial coordinate and velocity;

$P_{k}=D_{k} /\left(U_{0} \cdot r_{0}\right)=0.01, P_{0}=\lambda /\left(c_{p} \cdot \rho_{0} \cdot U_{0} \cdot r_{0}\right)=0.05, q_{1}=Q_{1} /\left(c_{p} \cdot T_{0}\right)=437$,

$q_{2}=Q_{2} /\left(c_{p} \cdot T_{0}\right)=157$

$Q_{1}=\left(m_{1} \cdot h_{1}+m_{2} \cdot h_{2}-m_{3} \cdot h_{3}-m_{4} \cdot h_{4}\right) /\left(m_{1} \cdot m\right)=131 \cdot 10^{6} \mathrm{~J} \cdot \mathrm{kg}^{-1}$,

$Q_{2}=\left(m_{2} \cdot h_{2}-m_{4} \cdot h_{4}+m_{5} \cdot h_{5}-m_{6} \cdot h_{6}\right) /\left(m_{2} \cdot m\right)=47 \cdot 10^{6} \mathrm{~J} \cdot \mathrm{kg}^{-1}$ are heat releases of reactions;

$\delta_{k}=E_{k} /\left(R \cdot T_{0}\right),\left(\delta_{1}=5.76, \delta_{2}=12.34\right)$ are the scaled activation-energy;

$\lambda=2.5 \cdot 10^{-1} \mathrm{~J} \cdot \mathrm{s}^{-1} \cdot \mathrm{m}^{-1} \cdot \mathrm{K}^{-1}$ is the thermal conductivity;

$D_{k}=2.510^{-4} \mathrm{~m}^{2} \cdot \mathrm{s}^{-1}$ is molecular diffusivity of species;

$A_{1}=A^{\prime}{ }_{1} \cdot \rho_{0} \cdot r_{0} /\left(U_{0} \cdot m_{2}\right), A_{2}=A^{\prime}{ }_{2} \cdot \rho_{0} \cdot r_{0}\left(U_{0} \cdot m_{5}\right),\left(A_{1}=6,353, A_{2}=1.7143 \cdot 10^{7}\right)$ are the scaled reaction-rate pre-exponential factors;

$R e=U_{0} \cdot r_{0} \cdot \rho_{0} / \mu=1000$ is the Reynolds number;

$\mu=5 \cdot 10^{-6} \mathrm{~kg} \cdot \mathrm{m}^{-1} \cdot \mathrm{s}^{-1}$ is the viscosity;

$e=10^{-5}$ is the factor of the artificial viscosity for approximation of the density.

The scaled values are: for inlet temperature and density $T_{0}=300 \mathrm{~K}, \rho_{0}=1 \mathrm{~kg} \cdot \mathrm{m}^{-3}$, for axial velocity $U_{0}=0.1 \mathrm{~m} \cdot \mathrm{s}^{-1}$, for length $r_{0}=0.05 \mathrm{~m}$ (radius of the combustor), for time $t_{0}=r_{0} / U_{0}=0.5 \mathrm{~s}$. For the dimensionless pressure $p$, we use a model of perfect gas: $p=\rho \cdot T$.

The boundary conditions at the inlet $(x=0): \rho=w=T=1, C_{3}=C_{4}=C_{6}=0, C_{1}=C_{10}, C_{2}=C_{20}$, $C_{5}=C_{50}$ (depend on pellets and their mixture). These values are used for initial conditions at $t=0$. In the outlet zero derivative conditions are used.

The numerical results of the main flame characteristics (Table 1) are obtained for $0<x<2$ and $0<t<1\left(w_{\max }=\max (w), w_{\text {end }}=w(2,1), T_{\max }=\max (T), T_{\text {end }}=T(2,1), C_{\text {kend }}=C_{k}(2,1), k=1(1) 6, C_{10}=\right.$ $C_{1}(x, 0), C_{50}=C_{5}(x, 0), C_{20}=C_{2}(x, 0)$ and are expressed with account of their time-dependent variations downstream of the combustor $(x, t)$. The results of numerical simulation have shown that the mass fraction of reactants $\mathrm{CO}, \mathrm{OH}$ decreases to zero by final time $t=0.5 \mathrm{~s}$. If $b_{1}=1.6, b_{2}=0.14$ the numerical results differ from [9] by about $1-2 \%$.

Table 1

Values of $C_{k e n d}, w_{\max }, w_{\text {end }}, T_{\text {end }}, T_{\max }$ for biomass pellets (wood, wheat straw) and their mixtures $\left(C_{2 e n d}=C_{5 e n d}=0\right)$

\begin{tabular}{|l|c|c|c|c|c|}
\hline $\begin{array}{l}\text { Concentration of } \\
\text { species }\end{array}$ & Wood & $\begin{array}{c}\text { Wood + } \\
\mathbf{1 0} \% \text { straw }\end{array}$ & $\begin{array}{c}\text { Wood + } \\
\mathbf{2 0} \% \text { straw }\end{array}$ & $\begin{array}{c}\text { Wood + } \\
\mathbf{3 0} \% \text { straw }\end{array}$ & Straw \\
\hline $\boldsymbol{C}_{10}\left(\mathbf{H}_{2}\right)$ & 0.22 & 0.24 & 0.20 & 0.17 & 0.30 \\
$\boldsymbol{C}_{50}(\mathbf{O H})$ & 0.36 & 0.52 & 0.46 & 0.38 & 0.50 \\
$\boldsymbol{C}_{20}(\mathbf{C O})$ & 0.42 & 0.24 & 0.34 & 0.45 & 0.20 \\
$\boldsymbol{C}_{1 \text { end }}\left(\mathbf{H}_{2}\right)$ & 0.197 & 0.231 & 0.192 & 0.144 & 0.290 \\
$\boldsymbol{C}_{3 \text { end }}\left(\mathbf{H}_{2} \mathbf{O}\right)$ & 0.213 & 0.056 & 0.075 & 0.230 & 0.036 \\
$\boldsymbol{C}_{4 \text { end }}(\mathbf{H})$ & 0.025 & 0.025 & 0.020 & 0.025 & 0.012 \\
$\boldsymbol{C}_{6 \text { end }}\left(\mathbf{C O}_{2}\right)$ & 0.570 & 0.593 & 0.697 & 0.600 & 0.430 \\
$\boldsymbol{w}_{\text {max }} \mathbf{~} \mathbf{m} \cdot \mathbf{s}^{-1}$ & 0.549 & 0.509 & 0.585 & 0.559 & 0.474 \\
$\boldsymbol{w}_{\text {end }}, \mathbf{m} \cdot \mathbf{s}^{-1}$ & 0.301 & 0.292 & 0.307 & 0.301 & 0.285 \\
$\boldsymbol{T}_{\text {end }}, \mathbf{K}$ & 1014 & 834 & 1020 & 963 & 750 \\
$\boldsymbol{T}_{\text {max }}, \mathbf{K}$ & 1419 & 1251 & 1624 & 1485 & 1083 \\
\hline
\end{tabular}

From the data presented in the Table 1 it follows that the maximal values of temperature, axial velocity and mass fraction of the main product $\left(\mathrm{CO}_{2}\right)$ are obtained for the mixture with $20 \%$ of straw mass load. For all mixtures the mass fraction of reactants $\mathrm{CO}, \mathrm{OH}$ in the reactions by $t=0.5 \mathrm{~s}$ decreases to zero, indicating incomplete combustion of $\mathrm{OH}$ for straw pallets with $C_{5 \text { end }}=0.230$.

The time dependent variations of the flame temperature, flow velocity, density and mass fraction of flame species (final time $t_{f}=1 \mathrm{~s}$ ) downstream of the combustor $(0<x<2)$ are illustrated in 
Fig. 1-4. For final time $(t=0.5 \mathrm{~s})$ the results of numerical simulation show a monotone increase of $\mathrm{w}$ with correlating decrease of flame density in axial direction (Fig. 1, a). The time-dependent variations of flow density in axial direction (Fig. 1, b) indicate an increase of the density at the inlet from $\rho=1$ $\left(1.0 \mathrm{~kg} \cdot \mathrm{m}^{-3}\right.$ at $t=0$ to its maximum value in a reaction zone $-1.67 \mathrm{~kg} \cdot \mathrm{m}^{-3}$ and then decreases to $\rho_{\text {end }}=0.184 \mathrm{~kg} \cdot \mathrm{m}^{-3}$.

The concentration of $C_{2}(\mathrm{OH})$ rapidly decreases from $C_{2}=0.34(t=0)$ at the inlet to zero for fixed time $0.5 \mathrm{~s}$ (Fig. 2, a). The concentration of the final product $C_{3}\left(\mathrm{H}_{2} \mathrm{O}\right)$ rapidly increases from zero at the inlet $(t=0)$ to its maximum value 0.087 in the reaction zone and in the final time decreases to asymptotical value 0.075 (Fig. 2, b). The concentration $C_{6}$ of the final product $\mathrm{CO}_{2}$ at the inlet and $t=0$ is equal to zero, then rapidly increases to its maximum value 0.740 in the reaction zone and in the final time decreases to asymptotical value 0.697 (Fig. 3, a). The axial velocity $w$ increases from $w=1$ $\left(0.1 \mathrm{~m} \cdot \mathrm{s}^{-1}\right)$ at the inlet $(t=0)$ to its maximum value $5.85\left(0.585 \mathrm{~m} \cdot \mathrm{s}^{-1}\right)$ in the reaction zone at $\mathrm{t}=0.351$ $(0.175 \mathrm{~s})$ and then decreases to $w_{\text {end }}=0.307 \mathrm{~m} \cdot \mathrm{s}^{-1}$ (Fig. 3, b). The flame temperature $T$ increases from $T=1(300 \mathrm{~K})$ at the inlet $(t=0)$ to its maximum value in the reaction zone $-5.414(1624 \mathrm{~K})$ at $t=2.5 \cdot 10^{-4} \mathrm{~s}$ and in the final time decreases to $T_{\text {end }}=3.395(1017 \mathrm{~K})$ (Fig. 4, a, b).

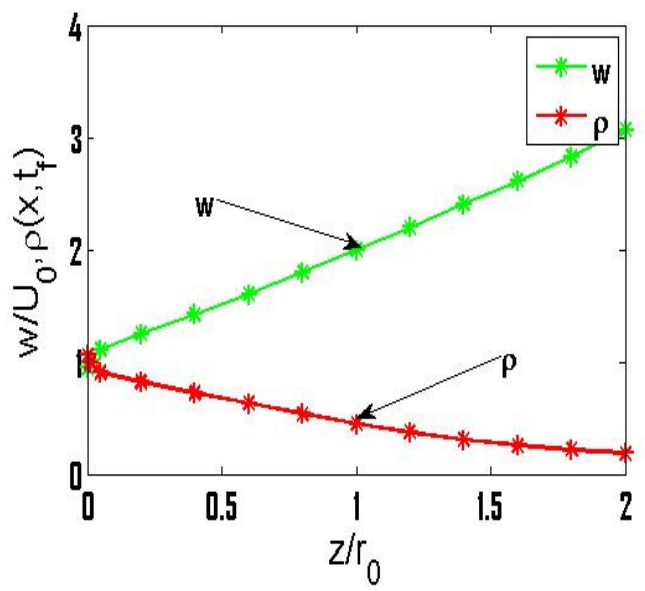

a

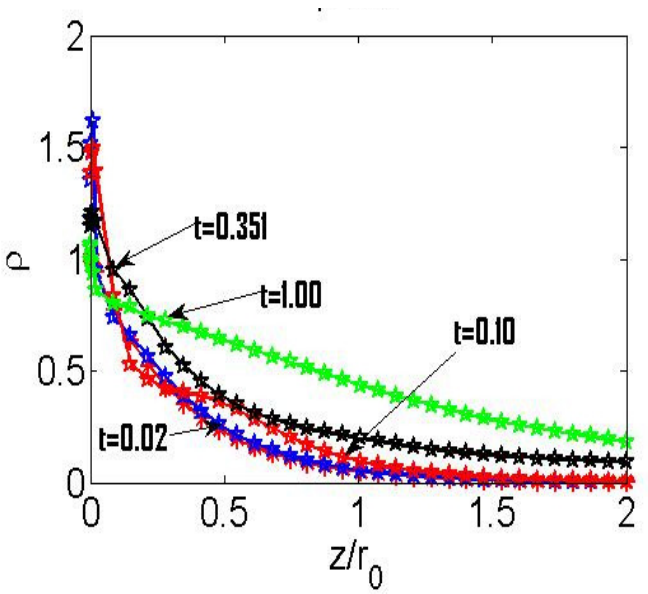

b

Fig. 1. Axial variation of $\mathrm{w}$ and $\rho$ on $\mathrm{x}$ for fixed time $t=t_{f}=0.5 \mathrm{~s} ; w_{\text {end }}=3.07\left(0.307 \mathrm{~m} \cdot \mathrm{s}^{-1}\right)$, $\rho_{\text {end }}=0.184\left(0.184 \mathrm{~kg} \cdot \mathrm{m}^{-3}\right)(\mathrm{a})$; time-dependent variations of $\rho$ on $x$; for $t_{f}=0.5 t \mathrm{~s}$, $\rho_{\text {max }}=1.67 \mathrm{~kg} \cdot \mathrm{m}^{-3}, \rho_{\text {min }}=0.0025 \mathrm{~kg} \cdot \mathrm{m}^{-3}, \rho_{\text {end }}=0.184(\mathrm{~b})$

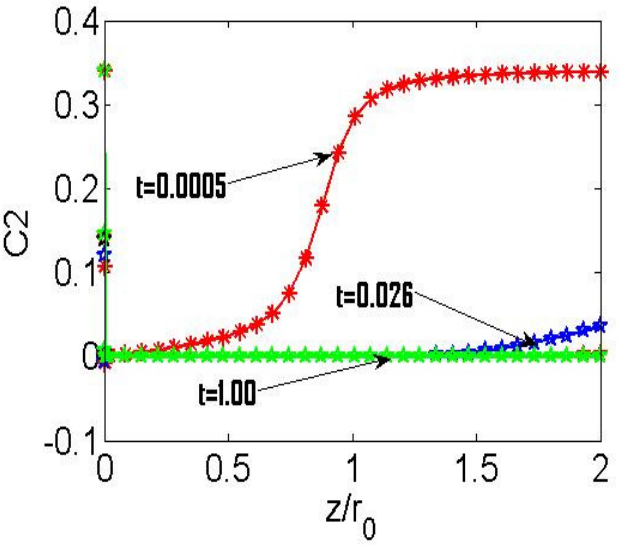

a

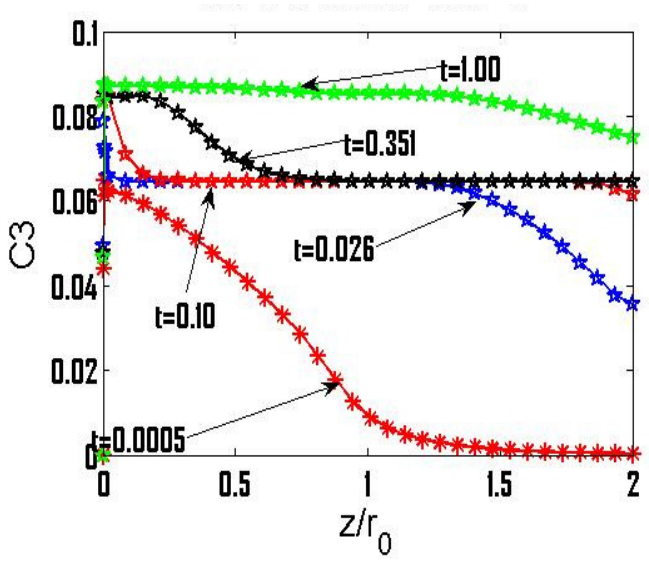

b

Fig. 2. Time dependent variations of $C_{2}(\mathrm{OH})$ on $x ; C_{20}=0.34$ for fixed time $0.5 t \mathrm{~s}, C_{2 e n d}=0$, of $C_{2}(\mathrm{OH})$ on $x$ (a); time dependent variations of $C_{3}\left(\mathrm{H}_{2} \mathrm{O}\right)$ on $\mathrm{x}$ for fixed time $0.5 t \mathrm{~s} C_{3 \text { end }}=0.0749$, $C_{3 \max }=\mathbf{0 . 0 8 7 3 ( b )}$ 


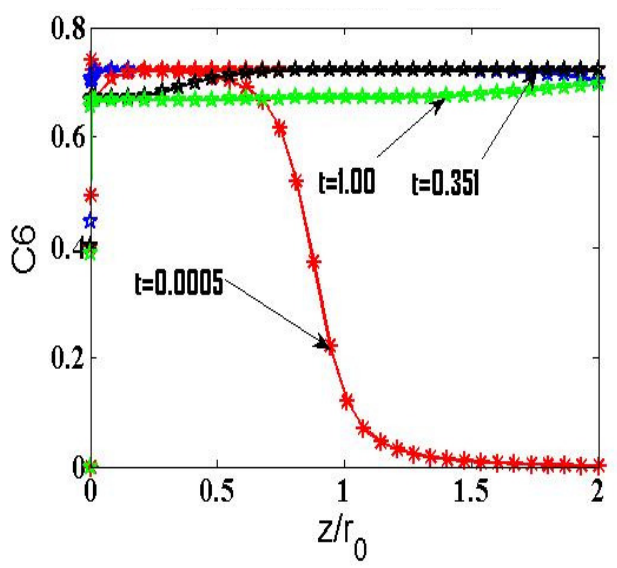

a

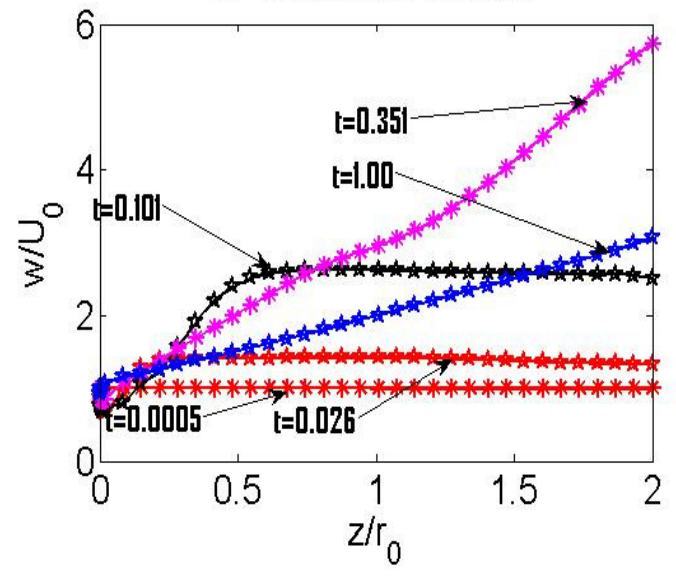

b

Fig. 3. Time dependent variations of $C_{6}\left(\mathrm{CO}_{2}\right)$ on $x$; for fixed time $0.5 t \mathrm{~s}, C_{6 \max }=0.740$, $C_{6 e n d}=0.697$ (a); time dependent variations of $w$ on $x$; for fixed time $0.5 \mathrm{t} \mathrm{s}, w_{\max }=5.85$ $\left(0.585 \mathrm{~m} \cdot \mathrm{s}^{-1}\right), w_{\text {end }}=3.07\left(0.307 \mathrm{~m} \cdot \mathrm{s}^{-1}\right)(\mathrm{b})$

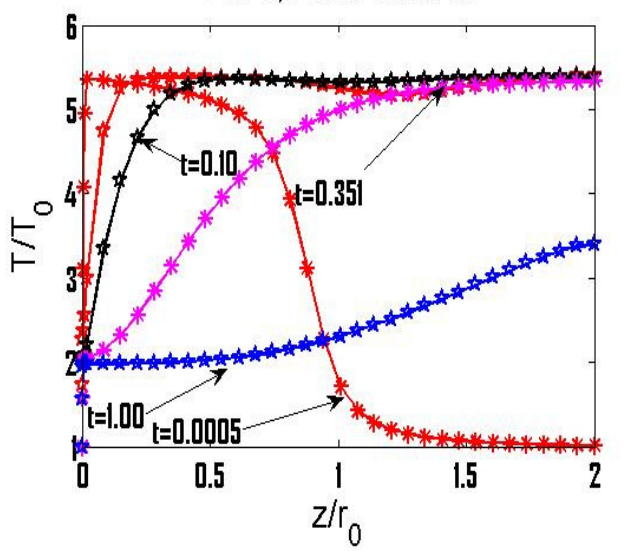

a

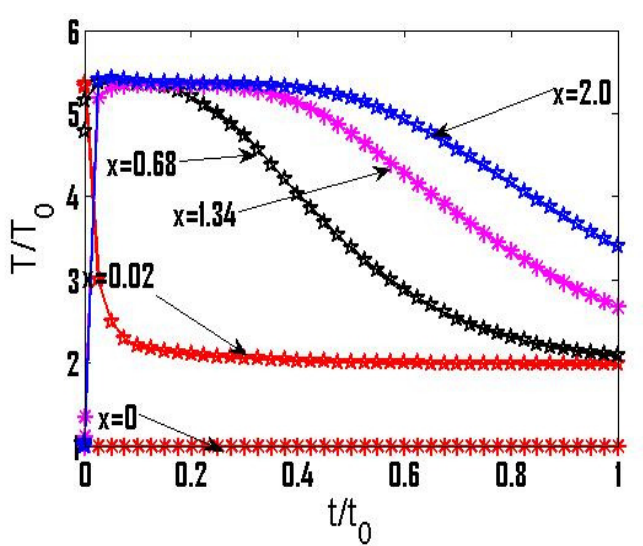

b

Fig. 4. Time dependent variations of $T$ on $x$ for fixed time $0.5 t \mathrm{~s}, T_{\max }=5.414(1624 \mathrm{~K})$, $T_{\text {end }}=3.395(1020 \mathrm{~K})(\mathrm{a})$; time dependent variations of $T$ for fixed $x, t_{0}=0.5 \mathrm{~s}, T_{\max }=1624 \mathrm{~K}(\mathrm{~b})$

\section{Experimental studies}

The effects of wheat straw co-gasification/co-combustion with wood pallets were studied using a batch-size pilot device, which combines a biomass gasifier and the water-cooled sections of a combustor [10]. The gasifier was filled with a mixture of straw and wood pellets by varying the mass load of straw in the mixture from 0 up to $100 \%$. The thermal decomposition of the mixture was initiated by an external heat source - by a propane flame flow with average heat input $1 \mathrm{~kW}$ and duration of the heat input up to $360 \mathrm{~s}$. The experimental study of the gasification/combustion characteristics at thermochemical conversion of the mixtures is carried out at average air excess in the flame reaction zone $\alpha \approx 1.6-1.7$. The experimental study involved joint measurements of the main characteristics (elemental composition, heating values) of straw pellets and their mixtures with wood, complex measurements of the mixture weight loss rate $(\mathrm{dm} / \mathrm{dt})$, composition of volatiles entering the combustor, local measurements of flame temperature, the products composition by the gas analyser Testo 350 and calorimetric measurements of the cooling water for the gasifier and the combustor.

The results of DTG analysis have shown [10] that the difference in chemical composition of wood and straw pellets results in faster thermal decomposition of straw with faster release, ignition and combustion of volatiles. By increasing the mass load of straw in a mixture up to $20 \%$, the heat release at combustion of volatiles promotes the thermal interaction between the components with enhanced heating and thermal decomposition of wood pellets and accelerates transition to flaming combustion of volatiles by varying the composition of volatiles entering the combustor, temperature of the reaction zone, heat energy production with improvement of combustion conditions and the composition of the 
products (Fig. 5, a to d), as it follows from the results of mathematical modelling and numerical simulation of the processes developing in the flame reaction zone (Fig. 1-4). At higher mass load of straw in the mixture $>30 \%$ dominates decrease of the produced heat energy in the device with correlating decrease of the heating value of the mixture (Fig. 5, c).
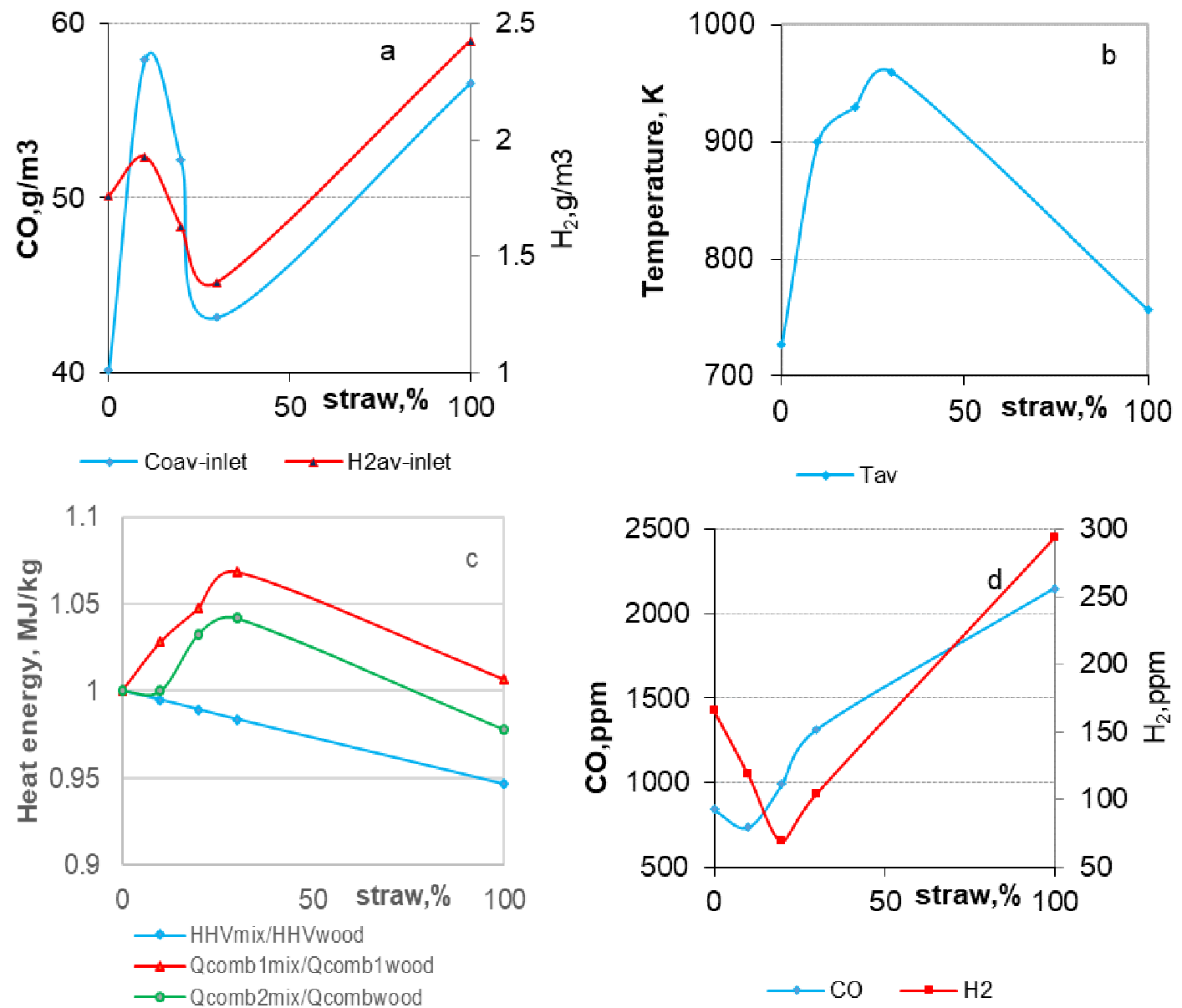

Fig. 5. Effect of mass load of straw in mixture at co-combustion of straw with wood pellets on formation of volatiles (a), temperature of reaction zone (b), produced heat energy per burned mass of mixture (c) and composition of products (d)

\section{Conclusions}

From the results of mathematical modeling and numerical simulation of the processes developing at combustion of volatiles downstream of the flame reaction zone the following conclusions can be drawn:

1. At thermo-chemical conversion of biomass pellets and their mixtures the maximal values of the temperature $T_{\max }$, axial flow velocity $w_{\max }$ and mass fractions of species $\mathrm{CO}_{2}$ are obtained during co-combustion $20 \%$ of straw with wood.

2. This is in accordance with the data of the experimental study indicating that the enhanced thermal decomposition at co-combustion of straw with wood and mass load of straw in the mixture up to $20 \%$ results in an enhanced transition to flaming combustion by increasing up to peak value temperature of the reaction zone, produced heat energy per mass of burned mixture (by about 4-8\%), improving the combustion condition and decreasing the mass fraction of unburned volatiles in the products with correlating in increase of the $\mathrm{CO}_{2}$ volume fraction in the products.

\section{Acknowledgements}

The authors would like to express their gratitude for financial support from the European Regional Funding for Project SAM 1.1.1.1./16/A/004. 


\section{References}

[1] Skøtt T., Straw to Energy, Status, Technologies and Innovation in Denmark, INBIOM, 2011, p. 39.

[2] Veijonen K., Vainikka P., Järvinen T., Alakangas E., Biomass co-firing an efficient way to reduce greenhouse gas emissions, European Bioenergy Networks, 2003, p. 26.

[3] Hardy T., Musialik-Piotrowska A., Ciolek J., Mošcicki K., Kordylewski W., Negative effects of biomass combustion and co-combustion in boilers, Environment Protection Engineering, vol. 38, No. 1, 2012, pp. 25-33.

[4] Olsson M., Wheat straw and peat for fuel pellets - organic compounds from combustion, Biomass and Bioenergy, vol. 30, 2006, pp. 555-564.

[5] Glithero N.J, Wilson P, Ramsden S.J. Straw use and availability for second generation biofuels in England. Biomass and Bioenergy, vol. 55, 2013; pp. 311-21.

[6] Barmina I., Valdmanis R., Zake M., The effects of biomass co-gasification and co-firing on the development of combustion dynamics, Energy, vol. 146, 2018, pp. 4-12.

[7] Barmina I., Valdmanis R., Zake M., Kalis H., The development of the gasification/combustion characteristics at thermos-chemical conversion of biomass mixtures, Engineering for rural development, 2017, pp. 34-59.

[8] Smooke M.D., Turnbull A.A., Mitchell R.E., Keyes D.E. Solution of two-dimensional axisymmetric laminar diffusion flames by adaptive boundary value methods. Proc. of the NATO Advanced Research Workshop on " Mathematical Modelling in Combustion and Related Topics" Lyon, France April 27-30, 1987, NATO ASI Series E: Applied Sciences, vol. 140, pp. 261-300.

[9] Powers J.M. Lecture notes on fundamentals of combustion. Univ. of Notre Dame, Indiana USA, 2012, pp. 5623-5637.

[10]Barmina I., Valdmanis R., Zake M., Co-firing of straw pellets with electrodynamic process control for clean and effective energy production, Proceedings of 25th European Biomass Conference and Exhibition (25 EUBCE), 2017, pp. 579-592. 